\author{
Ángel SÁnChez HeRnÁndez* \\ ORCID: 0000-0001-8196-3754
}

\title{
La Directiva (UE) 2019/633, en materia de prácticas comerciales desleales por una cadena de suministro agrícola y alimentario más equilibrada ${ }^{1}$
}

\section{Introducción}

\subsection{Antecedentes}

La transformación que ha experimentado el funcionamiento de la cadena de suministro agroalimentario ${ }^{2}$ ha originado alteraciones en la estructura de la demanda de los productos agroalimentarios, y como consecuencia, en las relaciones entre las empresas agroalimentarias. Uno de los cambios más importantes ha sido la concentración de empresas, en particular en el eslabón de la distribución ${ }^{3}$, en el que se han consolidado las figuras de los hipermercados y supermercados en sustitución del comercio minorista tradicional ${ }^{4}$.

* Universidad de la Rioja, España.

${ }^{1}$ Este trabajo se enmarca en el Proyecto de investigación rubricado: "La articulación orgánico -institucional y procedimental de la política económica de la Unión Europea en el marco del debate sobre la profundización de la Unión económica y monetaria y del futuro de Europa" (Referencia del proyecto es RTI 2018-093629-B-100 (MCIU/AEI/FEDER, UE).

${ }^{2}$ Que, entre otras causas, se debe al cambio de los gustos de los consumidores, al incremento de la población, y a los cambios regulatorios.

${ }^{3}$ Mientras la distribución está muy concentrada, la producción agroalimentaria está muy atomizada.

${ }^{4}$ En esta consolidación han influido factores como la creación de centrales de compra-que suministran productos a los puntos de venta-, la integración vertical -se integran diversas empresas con diferentes tareas en la cadena alimentaria que pertenecen al mismo grupo empresarial-, y el 
Esta situación ha fortalecido el poder de negociación de la gran distribución frente a sus proveedores y ha provocado que, en muchas ocasiones, sus relaciones comerciales sean desiguales originando desequilibrios y conflictos en la negociación entre compradores y proveedores.

En general, en cualquier negociación comercial en la cadena de suministro agrícola y alimentaria, el poder de negociación, en muchas ocasiones, lleva a forzar precios a la baja e imponer condiciones contractuales injustas que los proveedores aceptan para evitar ser expulsados del mercado. Algunas de las prácticas comerciales consisten bien en la inclusión de cláusulas ambiguas, de manera que durante la relación contractual, quien tiene mayor poder de negociación, puede imponer obligaciones adicionales a las acordadas previamente; o bien incorporar cláusulas relacionadas con las restricciones territoriales de suministro; o por último, solicitar información confidencial sobre los productos contratados, negándose a firmar un acuerdo de confidencialidad, o firmándolo no lo respetan, usando la información recibida en su provecho. Tales condiciones contractuales impuestas por la parte que se encuentra en situación de superioridad y que perjudican a la parte más débil, la que tiene menos poder de negociación y ninguna posibilidad de abandonar la relación comercial, -se les denomina prácticas comerciales desleales- ${ }^{5}$. Éstas no sólo van en detrimento de empresas agroalimentarias, sino también de los propios consumidores y del funcionamiento del mercado.

El hecho de que se produzcan desequilibrios en el poder de negociación entre compradores y proveedores en la cadena de suministro agrícola y alimentario puede impedir el correcto funcionamiento del mercado al faltar unas relaciones comerciales basadas en la claridad, en la transparencia y en la lealtad.

En España se ha tratado el problema de las prácticas comerciales desleales en la cadena alimentaria en la Ley 12/2013, de 2 de agosto, de medidas para mejorar el funcionamiento de la cadena alimentaria, a través, fundamentalmente, de la autorregulación (Código de Buenas Prácticas Mercantiles en la contratación alimentaria) y en la intervención administrativa (a través de la Agencia de Información y Control Alimentarios). Además, se cuenta con el Real Decreto-Ley 20/2018 que regula la prohibición de la venta a pérdidas con más seguridad jurídica.

desarrollo de las llamadas marcas blancas -o del distribuidor- para ofrecer precios bajos a los distribuidores y consumidores.

${ }^{5}$ Según fuentes del Parlamento Europeo las PYMES agrícolas y las dedicadas al procesamiento de alimentos pierden, como consecuencia de las prácticas comerciales desleales, entre 2500 y 8000 millones de euros al año, lo que equivale entre el 1\% y el 2\% de su facturación. 
Por otra parte, el Real Decreto-Ley 5/2020, de 25 de febrero, por el que se adoptan determinadas medidas urgentes en materia de agricultura y alimentación, en sus antecedentes, reconoce que "La confluencia de factores de diversa índole, como la caída sostenida de precios percibidos por los agricultores, [...]; las tensiones comerciales, la volatilidad de las cotizaciones de las materias primas, el incremento de los costes de los insumos agrarios y ganaderos, como la energía [...], y la falta de equilibrio en la fijación de precios en la cadena alimentaria, han conducido a una situación de crisis sin precedentes del sector agrario que obliga a los poderes públicos a intervenir de manera urgente $[\ldots]$.

Este fenómeno, que es común en países de nuestro entorno, ha propiciado que instituciones europeas han evidenciado la gravedad y extensión global de este problema, subrayando la necesidad de que los Estados adopten medidas, ampliando el marco normativo significativamente en tiempos recientes con una apuesta esencial a favor del reequilibrio de la cadena y ampliando notablemente el margen de acción para los Estados miembros. Las diferencias en el poder de negociación, que se corresponden con la dependencia económica del proveedor respecto del comprador, es probable que conduzcan a que los agentes más grandes impongan prácticas comerciales desleales a los agentes más pequeños.

Así, en el marco de la cadena de suministro agrícola y alimentario se producen con frecuencia desequilibrios importantes en cuanto a poder de negociación entre proveedores y compradores de productos agrícolas y alimentarios. Estos desequilibrios en el poder de negociación es probable que conduzcan a prácticas comerciales desleales, si los socios comerciales de mayor tamaño y poder tratan de imponer determinadas prácticas o disposiciones contractuales que les benefician en relación con una transacción de venta. Estas prácticas pueden, por ejemplo, apartarse en gran medida de las buenas conductas comerciales, ser contrarias a la buena fe y a un trato justo e imponerse de manera unilateral por una de las partes a la otra; o imponer una transferencia desproporcionada e injustificada de riesgo económico de las partes a la otra; o imponer un desequilibrio importante de derechos y obligaciones a una de las partes".

\subsection{Contextualización de la Directiva (UE) 2019/633}

El objetivo principal de la Directiva es el de evitar que se produzcan desequilibrios importantes en cuanto al poder de negociación entre proveedores y compradores en la cadena de suministro agrícola y alimentario. Se busca 
reforzar la posición de los proveedores más débiles y pequeños de la cadena de suministro de productos agrícolas y alimentarios ya que se encuentran en una situación de notable desventaja en el mercado.

Para ello se introduce un nivel mínimo de protección en la Unión Europea contra las prácticas comerciales desleales, ya que aún existen diferencias entre las normas que las regulan en los distintos Estados miembros de la Unión Europea. Se busca un marco normativo común que evite distorsiones y restricciones a la competencia en el mercado común cuando la relación comercial acontece entre empresas de los distintos Estados miembros de la Unión Europea.

La competencia desleal, como todo acto de competencia contrario a los usos honestos en materia industrial o comercial, no es un instrumento permitido legalmente para la tutela de los intereses de los empresarios. Su exclusión tiene por objeto la protección, en general, de todos los que participan en el mercado.

El acervo normativo de la Unión Europea ha regulado la competencia desleal centrándose en la represión de los actos en los que concurre esa competencia y que también pueden afectar, además de a los intereses de los empresarios, a los intereses de los consumidores ${ }^{6}$. No obstante, en los últimos años el Derecho de la Unión Europea ha prestado especial atención a la competencia desleal empresarial ${ }^{7}$, y en este contexto se inserta la Directiva (UE) 2019/633 del Parlamento Europeo y del Consejo, de 17 de abril de 2019, cuyo objetivo, según su artículo primero, es luchar contra las prácticas que se apartan manifiestamente de las buenas conductas comerciales, son contrarias a la buena fe y a la lealtad comercial y se imponen unilateralmente por una de las partes a la otra.

Para alcanzar este objetivo la susodicha Directiva establece una lista mínima de prácticas comerciales desleales prohibidas en las relaciones entre compradores y proveedores en la cadena de suministro agrícola y alimentario y dispone normas mínimas en relación con el control del cumplimiento de esas prohibiciones, así como disposiciones para la coordinación entre las autoridades encargadas de ese control del cumplimiento.

En el origen de esta Directiva se encuentran los desequilibrios importantes en cuanto al poder de negociación entre proveedores y compradores de productos agrícolas y alimentarios. En el concreto ámbito del sector vitivinícola, en los suministros de uva de los viticultores a las bodegas pueden

${ }^{6}$ Directiva 2005/29/CE relativa a las prácticas comerciales desleales de las empresas en sus relaciones con los consumidores en el mercado interior.

${ }^{7}$ Directiva 2006/114/CE, sobre publicidad engañosa y publicidad comparativa; Directiva (UE) 2016/943, sobre secretos comerciales. 
producirse desequilibrios en cuanto al poder de negociación que pudieran conducir a prácticas comerciales desleales si la empresa de mayor tamaño tratase de imponer determinadas disposiciones contractuales que les benefician en la venta efectuada. Se trataría de prácticas que, por ejemplo, por apartarse de las buenas conductas comerciales fuesen contrarias a la buena fe y a un trato justo, o se impusiese unilateralmente por una parte a la otra; o se impusiese una transferencia desproporcionada e injustificada de riesgo económico de una parte a la otra, o, por último, se impusiese un desequilibrio importante de derechos u obligaciones a una de las partes. Además, aun cuando ambas partes las acepten, determinadas prácticas pudieran ser manifiestamente desleales, por todo lo cual se ha de introducir una mínima protección contra esas prácticas evitando repercusiones negativas en el sector vitivinícola en particular ${ }^{8}$.

Los Estados miembros ya disponen de normas nacionales sobre prácticas comerciales desleales, aunque divergentes, por lo que una directiva constituye el instrumento adecuado para introducir un nivel mínimo de protección en el marco del Derecho comunitario, y de ese modo instaurar regímenes cohesivos. No se debe impedir que los Estados miembros mantengan e introduzcan en su territorio una normativa nacional más estricta que establezca un nivel de protección más elevado contra las prácticas comerciales desleales en las relaciones entre empresas ${ }^{9}$.

Por tanto, los Estados miembros deben tener la posibilidad de mantener o introducir normas nacionales concebidas para combatir prácticas comerciales desleales que no se ajusten al ámbito de aplicación de la Directiva 2019/633, pero dentro de los límites del Derecho de la Unión Europea aplicable al funcionamiento del mercado interior, y si dichas normas son proporcionadas ${ }^{10}$. Las susodichas normas nacionales se aplicarán con medidas de gobernanza voluntaria -códigos de conducta nacionales-. Se anima explícitamente a recurrir a la resolución alternativa de conflictos voluntaria entre proveedores y compradores, sin perjuicio del derecho del proveedor a presentar una denuncia o a buscar el amparo de los tribunales civiles.

En suma, los Estados miembros tendrán que adoptar y publicar las disposiciones legales y reglamentarias pertinentes para dar cumplimiento a la Directiva (UE) 2019/633, a más tardar el primero de mayo de 2021, y han de entrar en vigor a más tardar el primero de noviembre de $2021^{11}$.

\footnotetext{
${ }^{8}$ Directiva (UE) 2019/633, de 17 de abril de 2019, considerando 1.

9 Ibidem, considerando 39.

${ }^{10}$ Ibidem, considerando 40.

${ }^{11}$ Ibidem, art. 13.
} 


\section{La Directiva (UE) 2019/633, en materia de prácticas comerciales desleales en las relaciones entre empresas en la cadena de suministro de productos agrícolas y alimentarios: aspectos generales}

Los objetivos de la Directiva 2019/633, a saber, el establecimiento en toda la Unión de unas normas mínimas de protección mediante la armonización de las medidas divergentes de los Estados miembros en materia de prácticas comerciales desleales, no pueden ser alcanzados de manera aislada y suficiente por los Estados miembros y, sin embargo, pueden lograrse mejor en el ámbito del Ordenamiento Jurídico de la Unión Europea, ya que ésta puede adoptar medidas respecto del contrato de suministro con el principio de subsidiariedad establecido en el art. 5 del Tratado de la Unión Europea.

En España está vigente la Ley $12 / 2013$, de 2 de agosto, de medidas para mejorar el funcionamiento de la cadena alimentaria. Con la Directiva (UE) 2019/633 se profundizará en la protección de los productores-suministradores de productos agrícolas y alimentarios frente a determinadas prácticas en el marco de la cadena de suministro de los susodichos productos ya que la Directiva obliga a España a realizar las precisas adaptaciones de nuestro Ordenamiento Jurídico mediante su adecuada transposición. Además, todo ello implicará una mayor armonización de la legislación de los Estados miembros de la Unión Europea más allá de las prácticas desleales con consumidores, pasando ahora a alcanzar a las propias prácticas desleales entre empresas ${ }^{12}$.

\subsection{Los desequilibrios \\ en la cadena de suministro agrícola y alimentario en cuanto al poder de negociación entre proveedores y compradores de productos agrícolas y alimentarios pueden conducir a prácticas comerciales desleales}

Los productos agrícolas y alimentarios llegan al consumidor a través de la cadena de suministro en la que intervienen distintos agentes en sus distintas

12 F.J. Arias Varona, La armonización europea de la regulación de la Cadena alimentaria, La Ley mercantil, $n^{\circ}$ 60, julio 2019, p. 2, señala que el enfoque de la Directiva (UE) 2019/633 "hacia las prácticas comerciales desleales marca un claro cambio de la política jurídica de la UE. Como es sabido, la intervención legislativa europea ha omitido el régimen de la competencia desleal, salvo en el ámbito de las prácticas desleales con consumidores". 
fases de producción, transformación, comercialización, distribución y venta ${ }^{13}$ al por menor de dichos productos enumerados en el anexo I del Tratado de Funcionamiento de la Unión Europea, así como otros productos que si bien no figuran en el susodicho anexo han sido transformados como alimentos utilizando los productos del anexo mencionado.

No es nueva la preocupación del legislador ante ciertas prácticas desarrolladas en la cadena de suministro agrícola y alimentario. Hace tiempo que el legislador se percató de la necesidad de dotar de protección a los productores agrarios frente a determinadas prácticas que acontecen en su distribución. Los productores agrarios de pequeño tamaño, de menor tamaño que el de aquellos compradores de sus productos, se encuentran en una situación de debilidad contractual frente a éstos. Determinados comportamientos de las grandes empresas de distribución con los proveedores -sean agricultores, ganaderos, viticultores...- titulares de pequeñas explotaciones agrarias, encuentran explicación en el desequilibrio entre las partes contractuales motivado por las evidentes diferencias de tamaño. Por ello, ante la intervención de tan diversos agentes entre los que puede existir un desequilibrio contractual es muy importante la protección contra las prácticas comerciales desleales que pueden influir negativamente en el nivel de renta del productor agroalimentario ${ }^{14}$.

En las distintas etapas de la cadena de suministro agrícola y alimentario el número y tamaño de los intervinientes varía. Las diferencias en el poder de negociación entre las partes se corresponden -según la Directiva- con la dependencia económica del productor-proveedor respecto del comprador, lo que puede llevar a que los agentes de la cadena de mayor tamaño económico impongan prácticas comerciales desleales a los más pequeños, resultando perjudicadas estas pequeñas y medianas empresas que suministran esos productos y que cuentan con un volumen de negocios anual de hasta 350.000.000 euros ${ }^{15}$. Según la propia Directiva, una aproximación al poder de negociación relativo está en el volumen de negocios anual de los distintos agentes, siendo así que la Directiva establece categorías basadas en el volumen de negocios conforme a los que concede protección, excluyendo a agentes que no sean vulnerables o "que lo sean significativamente menor que sus homólogos o competidores más pequeños" $"$.

${ }^{13}$ La Directiva se aplica a las prácticas comerciales sea cual sea la fase de la comercialización en que se produzcan. Ibidem, considerando 15.

${ }^{14}$ Ibidem, considerando 5 y 6 .

15 Ibidem, considerando 9.

${ }^{16}$ Ibidem, considerando 14. 


\subsection{Justificación y ámbito de aplicación de la Directiva}

\subsubsection{Justificación}

La Directiva es necesaria dada la diversidad de regulaciones nacionales en la materia. Si bien buena parte de los Estados de la Unión Europea cuentan con regulación específica sobre este tema, subsisten lagunas normativas, así como diferentes contenidos normativos sobre el particular. Además, no todos los elementos de las prácticas comerciales desleales a tratar en el ámbito de la cadena de suministro alimentario estaban integrados en la normativa imperativa o de adopción voluntaria de los Estados miembros. Por ello, con la presente Directiva se pretende asegurar un estándar de protección europeo homogéneo para los productores proveedores de productos agrícolas y alimentarios.

Muchos Estados miembros de la Unión Europea disponen de normas internas para proteger a los productores-proveedores contra las prácticas comerciales desleales en sus relaciones con la cadena de suministro agroalimentario. En los Estados miembros de la Unión Europea, a los productores-proveedores les cabe acudir contra las prácticas comerciales desleales en sus relaciones con la cadena de suministro agroalimentario bien al Derecho de contratos, bien a la autorregulación del propio sector, pero el temor a represalias contra el denunciante de las susodichas prácticas limita la efectividad real de tales recursos normativos. Ante esa situación algunos Estados miembros confían a la Administración Pública el control del cumplimiento de las normas estatales sobre las citadas prácticas comerciales desleales ${ }^{17}$. Pero, más allá de este modo de actuar, se ha aprobado la nueva Directiva para aportar una protección que beneficia a los productores agrícolas proveedores de productos agrícolas y alimentarios (incluidas las organizaciones de productores y las asociaciones de organizaciones de productores en función de su poder de negociación relativo) incluyendo a las cooperativas ${ }^{18}$.

Es precisa una regulación específica como la de Directiva (UE) 2019/633 relativa a las prácticas comerciales desleales en la relaciones entre empresas en la cadena de suministro agrícola y alimentario ante la existencia de desequilibrios en cuanto al poder de negociación entre proveedores y compradores de productos agrícolas y alimenticios que hacen posible la imposición de prácticas que se aparten manifiestamente de las buenas conductas comerciales y frente a las que el régimen jurídico general ordinario, la aplicación en la práctica de las normas de autorregulación no proporciona la protección jurídica suficiente a los proveedores. Este efecto limitado frente

\footnotetext{
${ }^{17}$ Ibidem, considerando 8 .

18 Ibidem, considerando 10.
} 
a esas determinadas prácticas comerciales desleales tiene su origen en el riesgo de represalias comerciales a los proveedores debidas a las frecuentes diferencias de poder de negociación entre proveedores y compradores de productos agrícolas y alimentarios, por todo ello.

Así pues, el régimen jurídico específico de la Directiva se basa en la tutela de la parte débil ${ }^{19}$ estableciendo una lista mínima de prácticas comerciales desleales prohibidas en las relaciones entre compradores y proveedores en la cadena de suministro, estableciendo normas de carácter imperativo y con mecanismos de control del cumplimiento de esas prohibiciones, así como sanciones y disposiciones para la coordinación entre las autoridades encargadas de su cumplimento.

\subsection{2. Ámbito de aplicación}

La Directiva se aplicará a minoritas, a empresas de transformación de alimentos, a mayoristas, a las cooperativas u organizaciones de productores o a simples productores que realicen alguna de las prácticas comerciales desleales que se contemplan en sus disposiciones. Ahora bien, para definir en ámbito de aplicación de la norma la Directiva incluye umbrales para delimitar los supuestos de desequilibrio que exigen la aplicación de esta norma.

La Directiva se aplica a las relaciones en la cadena de distribución entre proveedores y compradores, personas físicas o jurídicas entre las que se realizan determinadas prácticas comerciales desleales en las ventas de productos agrícolas y alimentarios descritos en el art. 1.2 de la propia Directiva. Ésta se limita al mercado de los "productos agrícolas y alimentarios" incluidos en el Anexo I del Tratado Fundacional de la Unión Europea cuya finalidad es delimitar el ámbito de aplicación de la Política Agraria y Pesquera Común. La Directiva realiza la mentada remisión con la única finalidad tuitiva del productor agroalimentario en relación con las prácticas en el seno de la cadena de distribución.

En cuanto a los compradores, la Directiva (UE) 2019/633 se aplica a las transacciones comerciales, con independencia de si se realizan entre empresas o entre éstas y las Administraciones Públicas que compren los susodichos productos y deben someterse a las mismas normas ${ }^{20}$.

${ }^{19}$ La necesidad de protección de los productores agrícolas y alimentarios en muchas ocasiones se explica por ser la parte débil, por su menor tamaño respecto del comprador. No siempre es así, ya que algunos proveedores - vg. cooperativa agroalimentarias- han alcanzado mayor tamaño, o bien se trata de un proveedor que para ciertas zonas y determinados productos concentra la venta de ciertos productos agrarios y alimentarios.

20 Directiva (UE) 2019/633, considerando 11. 
Para delimitar la existencia de un desequilibrio importante en cuanto al poder de negociación entre proveedores y compradores de productos agrícolas y alimentarios y así poder luchar contra las prácticas que se puedan generar y que se aparten manifiestamente de las buenas conductas comerciales, la Directiva atiende al tamaño relativo de las partes de la relación proveedor y comprador en términos de volumen de negocios anual, entendiendo que en la distribución de productos alimentarios la parte débil es el proveedor siendo la parte fuerte la parte compradora. En este sentido la Directiva establece un esquema en escalada en función del volumen de facturación de forma que el desequilibrio queda determinado cuando el comprador se sitúa en la horquilla superior a la del vendedor indicada en el art. 1 apartado segundo de la Directiva UE) 2019/633.

La Directiva será de aplicación no sólo cuando los compradores y proveedores estén establecidos en el territorio de la Unión Europea, sino también cuando ello ocurre respecto de una de las partes, lo que supone una extraterritorialidad a los proveedores de la Unión Europea o extracomunitarios. Esto es, la Directiva protege a los proveedores de la Unión Europea contra las prácticas comerciales desleales de los compradores ya estén establecidos en un Estado de la Unión Europea o fuera de ella, evitando que los compradores puedan realizar la elección del lugar para establecerse en función de la normativa aplicable. A su vez, los proveedores establecidos fuera de la Unión Europea están protegidos cuando los compradores están establecidos en la Unión Europea, evitando así el desvío del comercio hacia proveedores no protegidos en detrimento de los proveedores de la propia Unión Europea ${ }^{21}$.

\section{Prohibición de prácticas comerciales desleales. Especificidad del sector vitivinícola}

La Unión Europea a través de la Directiva, como ya he señalado, pretende la armonización de la normativa de los Estados miembros que lucha contra las prácticas que se apartan manifiestamente de las buenas conductas comer-

${ }^{21}$ Ibidem, considerando 12. F.J. Arias Varona, La armonización europea..., p. 5, califica de "loable la intención de asegurar un nivel de protección máximo y de dotar de cierta flexibilidad al legislador nacional. Sin embargo, la opción elegida mantiene abierto el problema de la norma aplicable en las relaciones entre países distintos, algo cada vez más habitual por el funcionamiento de los mercados de compraventa de este tipo de productos para los grandes operadores. Precisamente la necesidad de acabar con esa divergencia explica el esfuerzo armonizador y cabría preguntarse si no hubiera sido más deseable una posición más rígida del legislador europeo que condujera a la armonización plena en esta materia”. 
ciales contrarias a la buena fe y lealtad comercial en la cadena de suministro agrícola y alimentario, asegurando una protección mínima al proveedor con independencia de la ubicación del comprador fuera o dentro del ámbito territorial de la Unión Europea. Para ello la Directiva determina un conjunto de prácticas comerciales que considera desleales y que los Estados de la Unión Europea prohíben, sin perjuicio de que en las normas internas de esos Estados se adopten posiciones más restrictivas respecto de tales prácticas ${ }^{22}$.

Dentro del listado de prácticas desleales contempladas por la Directiva destacan la preocupación por los plazos de pago y las modificaciones de las condiciones inicialmente pactadas e impuestas por la parte compradora, así como la documentación por escrito de las relaciones contractuales. Se trata de poner coto a desequilibrios importantes en cuanto al poder de negociación entre proveedores y compradores de productos agrícolas y alimentarios debido, en general, al mayor poder de negociación del comprador de tales productos -en ocasiones, grandes cadenas de distribución-.

La Directiva distingue diversos tipos de prohibiciones. Un primer tipo de prohibición en todo caso de ciertas prácticas -que se recogen en el art. 3.1-, un segundo tipo que se refiere a prácticas comerciales prohibidas a menos que se hayan acordado previamente de manera clara y sin ambigüedad en el contrato de suministro o en cualquier otro contrato posterior entre el proveedor y el comprador -art. 3.2-.

Las primeras prácticas se prohíben en todo caso por considerar que resultan prácticas con suficiente desequilibrio como para considerar que su aceptación es consecuencia de la importante debilidad de la parte proveedora. En cambio, en el segundo grupo de prácticas prohibidas se preserva un margen de autonomía de la voluntad de las partes, descansando la protección en reglas de transparencia y consentimiento nítido en la relación contractual ${ }^{23}$.

Hay prácticas comerciales que se consideran desleales de por sí y no deben sujetarse a la libertad contractual de las partes. Ahora bien, a la hora de decidir si una práctica comercial dada es desleal, conviene establecer una diferencia entre las prácticas previstas en términos claros e inequívocos en los contratos de suministros -o en acuerdos posteriores entre las partesy las prácticas desarrolladas cuando se haya iniciado la transacción y por tanto no acordadas de antemano: sólo se prohíben los cambios unilaterales y retroactivos de tales términos claros e inequívocos del contrato de suministro ${ }^{24}$.

\footnotetext{
${ }^{22}$ Directiva (UE) 2019/633, art. 9.

${ }^{23}$ Ibidem, considerando 16.

${ }^{24}$ Ibidem, considerando 13.
} 


\subsection{Prácticas estrictamente prohibidas}

Según se establece en el art. 3.1, los Estados miembros se asegurarán de que se prohíban, al menos, todas las siguientes prácticas comerciales desleales: las referidas a plazos de pago, cancelación de pedidos, modificación unilateral del contrato, pagos adicionales, pagos por pérdida o deterioro, ausencia de formalización por escrito, comportamiento referido al secreto empresarial, amenazas y compensaciones especiales.

Analizamos seguidamente todas las prácticas comerciales desleales que los Estados miembros se asegurarán de que sean prohibidas ${ }^{25}$ :

3.1.1. En cuanto a los plazos de pago el art. 3.1.a) de la Directiva, trata de evitar plazos de pago excesivamente largos, diferenciando según se pacten entregas periódicas o no, prohibiendo el uso de plazos superiores a 30 días para productos perecederos, o de 60 días para el resto. Se trata de evitar fijar plazos largos de entrega que escondan pagos con aplazamientos superiores a los permitidos. Sin embargo, el plazo máximo de pago no debería contabilizarse antes de que el comprador sepa el importe debido, de modo que los retrasos por este motivo que sean superiores a los plazos indicados, treinta o sesenta días desde la entrega, serían responsabilidad del proveedor, salvo que fuese el comprador quien, por el desequilibrio entre las partes contractuales, imponga ese retraso en la emisión de la factura sobrepasando los plazos indicados.

Difícilmente cabe calificar como práctica comercial desleal el incumplimiento de un plazo de pago cuando aún no se conoce por el comprador el importe a pagar, si bien también pudiera ser que el motivo por el que se cuestiona el importe a pagar esconda en realidad la imposición por el comprador plazos de pago superiores a los legalmente establecidos ${ }^{26}$

Para los productos agrícolas y alimentarios perecederos ${ }^{27}$, caso de la uva para vinificación -y mosto para producción de vino-, no es compatible con el comercio leal efectuar el pago de dichos productos más allá de 30 días des-

${ }^{25}$ Ibidem, art. 3.1.

${ }^{26}$ Según F.J. Arias Varona, La armonización europea..., p. 7, estos plazos máximos pueden ocasionar problemas en algunas modalidades empleadas en el sector agrario, concretamente alude a "contratos de venta de semilla cuyo pago se acuerda diferir al final de la cosecha. Aparentemente este tipo de cosas siguen sin tener soluciones óptimas en la Directiva, dado que no parecen cubiertas por las diferentes excepciones a la regla que, en este momento, no parece oportuno detallar aquí (véase lo dispuesto en el párrafo final del art. 3.1 de la Directiva 2019/633). En todo caso, el sistema de aplicación sobre la base del desequilibrio puede mitigar el problema, dado el usualmente mayor tamaño del vendedor, en el caso de las semillas (cuestión que en el caso de las normas españolas plantea mayores problemas)".

${ }^{27}$ El art. 2 en su apartado 5 de la Directiva (UE) 2019/633 entiende por productos agrícolas o alimentarios perecederos aquellos que por su naturaleza o por la fase de transformación en que 
pués de la entrega, 30 días desde la expiración del plazo de entrega acordado cuando los productos sean entregados de forma periódica o 30 días desde la fecha en que se fije el importe por pagar ${ }^{28}$. A los efectos de los plazos de pago contemplados, los plazos de entrega acordados no excederán en ningún caso de un mes.

Cuando el contrato de suministro no establezca la entrega periódica de los productos agrícolas y alimenticios perecederos no es compatible con el comercio leal efectuar el pago de dichos productos más allá de 30 días después de la fecha de entrega o después de la fecha en que se fije el importe pagadero, eligiéndose la fecha que sea posterior de las dos ${ }^{29}$. No obstante, cuando el comprador fije el importe pagadero, los plazos de pago empezarán a contar a partir del final del plazo de entrega acordado en el que se haya realizado.

Por consiguiente, la Directiva pone de manifiesto que deben prohibirse las prácticas de morosidad en el pago de productos agrícolas y alimentarios, incluida la de los perecederos, ya que esta práctica repercute negativamente en la viabilidad económica del proveedor, sin aportarle compensación a cambio.

Ahora bien, esta prohibición indicada en la letra a) del art. 3.1. no se aplicará $^{30}$, entre otros, en los contratos de suministro entre proveedores de uva y mosto $^{31}$ para producción de vino y sus compradores directos siempre que:

se encuentran podrían dejar de ser aptos para la venta dentro de los 30 días siguientes a su recolección, producción o transformación.

${ }^{28}$ Para otros productos agrícolas y alimentarios, más de 60 días después de que finalice el plazo de entrega acordado en que se hayan realizado las entregas, o más de 60 días después de la fecha en que se fije la cantidad pagadera para dicho plazo de entrega, eligiéndose la fecha que sea posterior de las dos (art. 3.1. a) de la Directiva (UE) 2019/633).

${ }^{29}$ Para otros productos agrícolas y alimentarios, más allá de 60 días después de la fecha de entrega o después de la fecha en que se fije el importe pagadero, eligiéndose la fecha que sea posterior de las dos (art. 3.1. a) de la Directiva (UE) 2019/633). No obstante, cuando el comprador fije el importe pagadero, los plazos de pago empezarán a contarse a partir de la fecha de entrega.

${ }^{30}$ La prohibición indicada en la letra a) del citado art. 3.1. se entenderá sin perjuicio de: las consecuencias de las moras y los recursos establecidos en la Directiva 2011/7/UE, que se aplicarán, como excepción a los plazos de pago establecidos en dicha Directiva, basándose en los plazos de pago establecidos en la Directiva 2019/633; de la posibilidad de que un comprador y un proveedor acuerden una cláusula de reparto de valor a tenor del art. 172 bis del Reglamento (UE) nº 1308/2013. Además, la prohibición indicada en la letra a) del art. 3.1. no se aplicará a los pagos: realizados por un comprador a un proveedor cuando dichos pagos se realizan en el marco del programa escolar contemplado en el art. 23 del Reglamento(UE) no 1308/2013; los realizados por entidades públicas que presten servicios de asistencia sanitaria en el sentido del art., apartado 4, letra b) de la Directiva 2011/7/UE y en los contratos de suministro entre proveedores de uva y mosto para la producción de vino y sus compradores directos en los términos que establece la Directiva 2019/633.

${ }^{31}$ La uva $-\mathrm{y}$, en su caso, el mosto para producción de vino- ha de considerarse producto perecedero ya que cabe esperar que no será apto para la venta en el plazo de 30 días a partir del último acto de recolección, producción o transformación por el proveedor, con independencia de que 
i) los términos de pago específicos para las transacciones de venta se incluyan en los contratos tipo que hayan sido declarados vinculantes por el Estado miembro en virtud del art. 164 del Reglamento (UE) $n^{\circ}$ 1308/2013 antes del 1 de enero de 2019, y que los Estados miembros renueven esta ampliación de los contratos tipo a partir de esa fecha sin cambios significativos de los términos de pago que vayan en detrimento de los proveedores de uva y mosto;

ii) y los contratos de suministro entre proveedores de uva y mosto para producción de vino y sus compradores directos sean plurianuales o se conviertan en plurianuales.

Así pues, en relación con las disposiciones sobre mora, en el ámbito de la Directiva se entiende que las uvas y el mosto para la producción vinícola tienen características especiales ya que aun cuando las uvas se vendimian únicamente durante un periodo limitado en el año, sin embargo, se usan para la producción de vino, cuya venta puede no efectuarse hasta muchos años después. Muchos vinos con Denominación de Origen son envejecidos ${ }^{32}$ y ante esa situación especial, las organizaciones de productores e interprofe-

el productor sea sometido a nueva transformación o que sea manipulado tras su venta de acuerdo con otras normas aplicables, en particular las relativas a la seguridad alimentaria.

${ }^{32}$ Ley 6/2015, de 12 de mayo, de Denominaciones de Origen e Indicaciones Geográficas Protegidas de ámbito territorial supraautonómico. Disposición adicional segunda. Indicaciones relativas a las características de los vinos. A efectos de su protección, y sin perjuicio de las competencias que puedan tener las comunidades autónomas en materia de denominaciones de origen e indicaciones geográficas protegidas, se establecen las siguientes indicaciones relativas a las menciones de envejecimiento:

a) Indicaciones comunes para los vinos acogidos a una DOP o IGP correspondientes a la categoría 1 del anexo VII, parte II, del Reglamento (UE) n. ${ }^{\circ}$ 1308/2013 del Parlamento Europeo y del Consejo, de 17 de diciembre de 2013, por el que se crea la organización común de mercados de los productos agrarios y por el que se derogan los Reglamentos (CEE) n. ${ }^{\circ}$ 922/72, (CEE) n. ${ }^{\circ} 234 / 79,(\mathrm{CE})$ n. ${ }^{\circ} 1037 / 2001$ y (CE) n. ${ }^{\circ} 1234 / 2007$ :

«Noble», que podrán utilizar los vinos sometidos a un período mínimo de envejecimiento de dieciocho meses en total, en recipiente de madera de roble de capacidad máxima de 600 litros o en botella.

«Añejo», que podrán utilizar los vinos sometidos a un período mínimo de envejecimiento de veinticuatro meses en total, en recipiente de madera de roble de capacidad máxima de 600 litros o en botella.

«Viejo», que podrán utilizar los vinos sometidos a un período mínimo de envejecimiento de treinta y seis meses, cuando este envejecimiento haya tenido un carácter marcadamente oxidativo debido a la acción de la luz, del oxígeno, del calor o del conjunto de estos factores.

b) Además de las indicaciones reguladas en el párrafo anterior, los vinos con DOP correspondientes a la categoría 1 del anexo VII, parte II, del Reglamento (UE) 1308/2013 del Parlamento Europeo y del Consejo, de 17 de diciembre, podrán utilizar las siguientes:

«Crianza», que podrán utilizar los vinos tintos con un período mínimo de envejecimiento de veinticuatro meses, de los que al menos seis habrán permanecido en barricas de madera de roble de capacidad máxima de 330 litros; y los vinos blancos y rosados con un período mínimo 
sionales han elaborado contratos tipos para el suministro de uvas y mosto, en los que se prevén pagos fraccionados con plazos específicos. El uso de estos contratos tipos en acuerdos plurianuales proporciona no sólo seguridad de unas relaciones comerciales de larga duración, sino que contribuye también a la estabilidad de la cadena de suministro.

En este contexto, las disposiciones en materia de mora establecidas en la Directiva no se aplicarán a los contratos entre proveedores de uvas y mosto para la producción vinícola y sus compradores directos, cuando dichos contratos tipo -elaborados por organizaciones de productores, organizaciones interprofesionales o asociaciones de organizaciones de productores reconocidas- hayan sido declarados obligatorios por los Estados miembros ${ }^{33}$ con arreglo al art. 164 del Reglamento (UE) 1308/2013 antes del 1 de enero de 2019, o cuando los Estados miembros hayan prorrogado los contratos tipo sin haber efectuado modificaciones significativas de las condiciones de pago en detrimento de los proveedores de uvas y mosto ${ }^{34}$.

En el art. 164.1 del Reglamento (UE) 1308/2013 del Parlamento Europeo y del Consejo de 17 de diciembre de 2013 por el que se crea la Organización Común de Mercados de los productos agrarios, y que se refiere a la extensión de normas, se establece que: "En caso de que una organización de productores reconocida, una asociación reconocida de organizaciones de productores o una organización interprofesional reconocida que opere en una o varias

de envejecimiento de dieciocho meses, de los que al menos seis habrán permanecido en barricas de madera de roble de la misma capacidad máxima.

«Reserva», que podrán utilizar los vinos tintos con un período mínimo de envejecimiento de treinta y seis meses, de los que habrán permanecido al menos doce en barricas de madera de roble de capacidad máxima de 330 litros, y en botella el resto de dicho período; los vinos blancos y rosados con un período mínimo de envejecimiento de veinticuatro meses, de los que habrán permanecido al menos seis en barricas de madera de roble de la misma capacidad máxima, y en botella el resto de dicho período.

«Gran reserva», que podrán utilizar los vinos tintos con un período mínimo de envejecimiento de sesenta meses, de los que habrán permanecido al menos dieciocho en barricas de madera de roble de capacidad máxima de 330 litros, y en botella el resto de dicho período; los vinos blancos y rosados con un período mínimo de envejecimiento de cuarenta y ocho meses, de los que habrán permanecido al menos seis en barricas de madera de roble de la misma capacidad máxima, y en botella el resto de dicho período.

c) Indicaciones propias de los vinos espumosos de calidad. Podrán utilizar las siguientes indicaciones:

«Premium» y «reserva», que podrán utilizar los vinos espumosos de calidad definidos en la normativa europea y los vinos espumosos con DOP. «Gran reserva», que podrán utilizar los vinos con DOP «Cava», con un período mínimo de envejecimiento de treinta meses contados desde el tiraje hasta el degüelle.

${ }^{33}$ Directiva (UE) 2019/633, art. 3.1 in fine.

${ }^{34}$ Ibidem, considerando 19. 
circunscripciones económicas de un Estado miembro sea considerada representativa de la producción, el comercio o la transformación de un producto dado, el Estado miembro podrá disponer, previa solicitud de la organización, que algunos de los acuerdos, decisiones o prácticas concertadas pactadas en el marco de dicha organización sean obligatorias, por un periodo limitado, para otros operadores, tanto individuales como agrupados, que operen en esa o esas circunscripciones económicas y no pertenezcan a la organización o asociación".

La extensión de las normas previstas en el susodicho apartado 1 del art. 164 debe ponerse en conocimiento de los operadores mediante su inclusión completa en una publicación oficial del Estado miembro, según establece el apartado 5 de ese mismo art. 164 del Reglamento 1308/2013 de la Unión Europea. Esto es lo que se hace en España por la Orden APA/ 806/2019, de 25 de julio, por la que se extiende el Acuerdo de la Organización Interprofesional del Vino de España al conjunto del sector y se fija la aportación económica obligatoria para realizar actividades de promoción e información del sector vitivinícola y sus productos, inteligencia económica, vertebración sectorial, investigación, desarrollo, innovación tecnológica y estudios, durante las campañas 2019/2020, 2020/2021, 2021/2022, 2022/2023 y 2023/2024.

A) En el preámbulo de este texto reglamentario -Orden APA/ $\mathbf{8 0 6 / 2 0 1 9 , ~ d e ~} 25$ de julio- se recuerda que "El artículo 8 de la Ley 38/1994, de 30 de diciembre, reguladora de las organizaciones interprofesionales agroalimentarias establece que adoptado un acuerdo en el seno de una organización interprofesional agroalimentaria, relativo a actividades relacionadas con las finalidades definidas en el artículo 3 de dicha ley que cuenten con un determinado nivel de respaldo podrán extenderse al conjunto de productores y operadores del sector o producto [...] La Organización Interprofesional del vino de España, OIVE, ha propuesto la extensión de normas al conjunto del sector, con aportación económica obligatoria para realizar actividades de promoción e información del sector vitivinícola y sus productos, inteligencia económica, vertebración sectorial y desarrollar programas de investigación, desarrollo, innovación tecnológica y estudios, durante el periodo comprendido entre el 1 de agosto de 2019 y el 31 de julio de 2024".

El ministro de Agricultura, según el art. 1 de la Orden APA/806/2019, de 25 de julio, aprueba la extensión de normas al conjunto del sector del vino, del acuerdo de la Organización Interprofesional del Vino de España, OIVE, para realizar actividades de promoción e información del sector vitivinícola y sus productos, inteligencia económica, vertebración sectorial y desarrollar 
programas de investigación, desarrollo, innovación tecnológica y estudios, con aportaciones económicas para financiar las mismas, de los operadores del sector vitivinícola en España.

Entre las finalidades de la extensión de la norma se encuentra, según se establece en el art. 3.3. a) de la Orden APA/806/2019 el "fomento de la estabilidad de la cadena de valor del vino. Elaboración, difusión y promoción del empleo de contratos tipo homologados para la compraventa de uva y de vino. Explotación de la información agregada que resulte de los mismos. Actividades y materiales divulgativos y formativos dirigidos a los viticultores".

B) El contrato tipo de compraventa de uva con destino a su transformación en vino que regirá durante la campaña 2020/2021 ha sido homologado por la Orden APA/770/2020. En su preámbulo se dice que "vista la solicitud de homologación del contrato-tipo de compraventa de uva con destino a su transformación en vino, formulada por la Organización Interprofesional del Vino de España, OIVE, acogiéndose a los requisitos previstos en la Ley $2 / 2000$, de 7 de enero, reguladora de los contratos tipo de productos agroalimentarios, en el Real Decreto 686/2000, de 12 de mayo, por el que se aprueba su Reglamento ${ }^{35} \mathrm{y}$, de conformidad con la propuesta elevada por la Dirección General de la Industria Alimentaria, a fin de que los solicitantes puedan disponer de un documento acreditativo de la contratación de materia prima ante el Ministerio de Agricultura, Pesca y Alimentación [...]" se homologa -según la disposición primera de la susodicha orden ministerial- según el régimen establecido en la Ley $2 / 2000$, de 7 de enero, reguladora de los contratos tipo de productos agroalimentarios y el Real Decreto 686/2000, de 12 de mayo, por el que se aprueba el Reglamento de dicha Ley, el contrato-tipo de compraventa de uva con destino a su transformación en vino que regirá durante la campaña 2020/2021, cuyo texto figura en el anexo de la propia orden.

C) En cuanto al contenido del contrato tipo homologado de compraventa de uva con destino a su transformación en vino, que se encuentra en el Anexo de la citada orden, además de referirse a los intervinientes -vendedor y comprador-, (que formalizan el contrato tipo y surte efectos respecto de la obligación de formalizar los contratos alimentarios por escrito

${ }^{35}$ Sobre estos textos legales vide G. Doménech Martínez, Las organizaciones interprofesionales en las disposiciones normativas españolas y la contratación de productos agroalimentarios, en E. Muñiz Espada, P. Amat Llombart (dir.), Tratado de Derecho Agrario, Madrid 2017, pp. 385 a 441. De la misma autora, Comercialización de los productos agroalimentarios a través de los contratos tipo de productos agroalimentarios y la mediación en la resolución de sus controversias, "Revista de Derecho Agrario y Alimentario" 2012, nº 60, pp. 47 a 64. 
establecida por la Ley 12/2013, de 2 de agosto, de medidas para mejorar el funcionamiento de la cadena alimentaria), contendrá las estipulaciones referidas al objeto del contrato, precio, forma de pago y facturación, condiciones de entrega, recepción y control, recolección y transporte, duración, modificaciones y requisitos formales, tratamientos fitosanitarios, incumplimiento, extinción, comisión de seguimiento en el seno de la OIVE, funciones y financiación, resolución de conflictos, protección de datos y, por último, información que deben suministrar las partes.

C.1) En concreto, en cuanto al precio, la Orden APA/770/2020, de 27 de julio, por la que se homologa el contrato-tipo de compraventa de uva con destino a su transformación en vino que regirá durante la campaña 2020/2021, en cláusula segunda del contrato tipo establece que: "El precio aplicable en este contrato para uva que cumpla las estipulaciones señaladas será el resultado de aplicar el precio libremente pactado entre las partes, las primas o descuentos que procedan de acuerdo con los criterios o parámetros de calidad que se establezcan [...]".

En este aspecto hemos de tener presente la principal novedad en el ámbito de la cadena alimentaria, introducida por el Real Decreto-ley 5/2020, de 25 de febrero, por el que se adoptan determinadas medidas urgentes en materia de agricultura y alimentación y que consiste en "obligar a que cada operador abone al inmediatamente anterior un precio igual o superior al coste de producción de tal producto en que haya incurrido dicho operador, de modo que se preserve ese valor agregado creciente que fundamenta uno de los ejes vertebradores de la acción pública en este sector [...]. Asimismo, se previene que el operador que realice la venta final de producto al consumidor no pueda repercutir a ninguno de los operadores anteriores el riesgo empresarial derivado de su política comercial en materia de precios ofertados al público.

También se prevé como novedad destacada la inclusión del coste de producción en el precio como elemento mínimo de los contratos [...], se tiene en cuenta en la composición del precio el conjunto de factores objetivos, verificables y no manipulables que deben ser expresamente establecidos en el contrato [...] la norma incorpora una lista ejemplificativa de elementos para las explotaciones agrarias, tales como semillas, fertilizantes, pesticidas, energía o maquinaria, e índices que, entre otros, pueden emplearse para asegurar esa objetividad en su determinación, como los publicados por el Ministerio de Agricultura, Pesca y Alimentación. Esta medida [...] permite cohonestar la libre formación de la voluntad y la autorregulación de la oferta y demanda con el aseguramiento de que esos costes efectivos de producción que, además deberán cubrirse con el precio y aparecer así en el contrato, no se destruyen en estadios sucesivos de la cadena". 
En consecuencia, el Real Decreto-ley 5/2020, en su artículo primero, apartado uno, modifica la letra c) del apartado 1 del art. 9 de la Ley $12 / 2013$, de 2 de agosto, de medidas para mejorar el funcionamiento de la cadena alimentaria, que queda redactada como sigue y se añade una nueva letra j): “«c) Precio del contrato alimentario, con expresa indicación de todos los pagos, incluidos los descuentos aplicables, que se determinará en cuantía fija o variable. En este último caso, se determinará en función únicamente de factores objetivos, verificables, no manipulables y expresamente establecidos en el contrato. En ningún caso se utilizarán factores que hagan referencia a precios participados por otros operadores o por el propio operador. Los factores que emplean podrán ser, entre otros, la evolución de la situación del mercado, el volumen entregado y la calidad o composición del producto. En todo caso, uno de los factores deberá ser el coste efectivo de producción del producto objeto del contrato, calculado teniendo en cuenta los costes de producción del operador efectivamente incurridos, asumidos o similares. En el caso de las explotaciones agrarias se tendrán en cuenta factores tales como las semillas y plantas de vivero, fertilizantes, pesticidas, combustibles y energía, maquinaria, reparaciones, costes de riego, alimentos para los animales, gastos veterinarios, trabajos contratados o mano de obra asalariada. Se entenderá por factores objetivos aquéllos que sean imparciales, fijados con independencia de las partes y que tengan como referencia datos de consulta pública. En el caso de las explotaciones agrarias, éstos serán tales como los datos relativos a los costes efectivos de las explotaciones publicados por el Ministerio de Agricultura, Pesca y Alimentación».

«j) Indicación expresa de que el precio pactado entre el productor primario agrario, ganadero, pesquero o forestal o una agrupación de éstos y su primer comprador cubre el coste efectivo de producción».

También el Real Decreto-ley 5/2020 en su artículo primero apartado tres añade un nuevo art. 12 ter. con el siguiente contenido: «Destrucción de valor en la cadena. Con el fin de evitar la destrucción del valor en la cadena alimentaria, cada operador de la misma deberá pagar al operador inmediatamente anterior un precio igual o superior al coste efectivo de producción de tal producto en que efectivamente haya incurrido o asumido dicho operador. La acreditación se realizará conforme a los medios de prueba admitidos en Derecho.

El operador que realice la venta final del producto al consumidor en ningún caso podrá repercutir a ninguno de los operadores anteriores su riesgo empresarial derivado de su política comercial en materia de precios ofertados al público». 
Por último, el Real Decreto-ley 5/2020, en su artículo primero apartado dos, añade un nuevo art. 12 bis con el siguiente contenido: «Actividades promocionales. 1. En el ámbito de aplicación de esta ley: 1. El lanzamiento y desarrollo de promociones deberá realizarse basándose en los principios de: a) acuerdo y libertad de pactos; b) interés mutuo; y c) flexibilidad para adaptarse a las circunstancias particulares de los distintos operadores.

2. Los pactos sobre promociones comerciales se respetarán en su naturaleza e integridad. Dichos pactos, que deberán contar con el acuerdo explícito de ambas partes, recogerán los aspectos que definen la promoción: los plazos (fechas de inicio y finalización), los precios de cesión, los volúmenes, y aquellas otras cuestiones que sean de interés, así como también los aspectos de la promoción relativos al procedimiento, el tipo, el desarrollo, la cobertura geográfica y la evaluación del resultado de ésta.

3. No se realizarán actividades promocionales que induzcan a error sobre el precio e imagen de los productos o que perjudiquen la percepción en la cadena sobre la calidad o el valor de los productos»".

En este sentido, las actividades promocionales que se realicen en el ámbito de aplicación de la ley de la cadena han de desplegarse "en un marco equitativo de obligaciones y derechos, entre los que cabe destacar que se base en el acuerdo y libertad de pactos, para los cuales se establecen unos contenidos mínimos; el interés mutuo; y la flexibilidad para adaptarse a las circunstancias particulares de los distintos operadores, sin que puedan realizarse actividades particulares de los distintos operadores, sin que puedan realizarse actividades promocionales entre los mismos que induzcan a error sobre el precio e imagen de los productos, con el fin de evitar que se perjudique la percepción en la cadena sobe la calidad o valor de los productos, banalizando una actividad esencial para la economía y sociedad."

C.2) En cuanto a la forma de pago y facturación, la Orden APA/770/2020, de 27 de julio, por la que se homologa el contrato-tipo de compraventa de uva con destino a su transformación en vino que regirá durante la campaña 2020/2021, en la cláusula tercera establece que "el pago se hará en la forma que las partes libremente establezcan dentro de los límites marcados por la normativa aplicable. De forma general, quedarán prohibidas aquellas modalidades de pago que supongan un aplazamiento de pago". Se prevé una entrega a cuenta.

El vendedor está obligado a entregar factura al comprador antes de que transcurran quince (15) días desde la recepción efectiva de la mercancía, conforme al art. 4.1 de la Ley $3 / 2004$, de 29 de diciembre, por las que se establecen las medidas de lucha contra la morosidad en las operaciones comerciales, considerándose esta fecha de recepción efectiva el último día 
de la entrega, con el IVA correspondiente y en la que figurará la cantidad de uva y el precio pactado.

En el caso de que el vendedor esté acogido al Régimen especial de la agricultura, ganadería y pesca será el adquirente el que expida el correspondiente recibo agrario de acuerdo con la normativa vigente.

El pago se realizará a los ... días contados desde la fecha de finalización de la entrega de la uva, considerada según lo señalado en el párrafo anterior, y siempre dentro de los 30 días siguientes a esta fecha.

En aquellas Denominaciones de Origen, Indicaciones Geográficas Protegidas u otras figuras de calidad en las que esté establecido un sistema de «validación de la cosecha», si de dicha validación resultare un precio superior, el día inicial del plazo de pago de la diferencia hasta dicho precio es el de la comunicación fehaciente por parte del organismo de control de la figura de calidad al comprador y al vendedor del resultado de la verificación.

Por último, la cláusula tercera del contrato tipo establece que serán de aplicación los plazos de la Directiva 2011/7/UE, del Parlamento Europeo y del Consejo, de 16 de febrero de 2011, de la Ley 3/2004, de 29 de diciembre, por las que se establecen las medidas de lucha contra la morosidad en las operaciones comerciales y de la Disposición adicional primera de la Ley 15/2010, de 5 de julio, de modificación de la Ley 3/2004, de 29 de diciembre.

3.1.2. En segundo lugar, la Directiva (UE) 2019/633, considera desleal las cancelaciones de pedidos de productos agrícolas y alimentarios perecederos con un plazo menor de 30 días, ya que el proveedor no estará en disposición de encontrar una salida alternativa para dichos productos. Los Estados miembros de la Unión Europea podrán establecer periodos inferiores a 30 días para sectores específicos y en casos debidamente justificados en que los productores de determinados sectores, en unos plazos de cancelación más cortos de esos 30 días, pueden tener todavía tiempo suficiente para que los proveedores vendan los productos en otro punto o les den ellos mismos uso ${ }^{36}$.

Según el art. 3.1 letras b y c, se considera desleal la cancelación o modificación unilateral del contrato por los compradores que, gozando de una posición más fuerte, modifican de forma unilateral las cláusulas contractuales acordadas -vg. suprimir productos objeto de un contrato de suministro-.

En cuanto a la modificación unilateral del contrato, se considera práctica comercial desleal que el comprador modifique unilateralmente los términos del contrato de suministro de productos agrícolas y alimentarios en perjuicio de los proveedores, en lo que se refiere a la frecuencia, método, lugar, ca-

${ }^{36}$ Directiva (UE) 2019/633, considerando 20 y art. 3.1. b. 
lendario o volumen del suministro o la entrega de tales productos, la norma de calidad, las condiciones de pago o los precios. No obstante, no resulta aplicable a las situaciones en las que exista un contrato entre un proveedor y un comprador en el que se estipule expresamente que éste último podrá especificar más adelante un elemento concreto de la transacción con respecto a pedidos futuros -vg. las cantidades encargadas-. Esto es, los acuerdos no necesariamente se celebran en un momento dado para todos los aspectos de la transacción entre el proveedor y el comprador ${ }^{37}$.

Se trata de prohibir sobre todo "cambios unilaterales y con carácter retroactivo de esos términos claros e inequívocos del contrato de suministro" 38 en lo que se refiere a la frecuencia, método, lugar, calendario o volumen del suministro o la entrega de tales productos, la norma de calidad, las condiciones de pago o los precios.

Para las modificaciones unilaterales, distintas de la cancelación de pedidos, la Directiva incorpora un listado de modificaciones prohibidas que están detalladas -art.3.1. c)-, por lo que aquellas que no están detalladas cabe considerarlas lícitas por las legislaciones nacionales ${ }^{39}$.

En cuanto a la cancelación, se considera práctica comercial desleal que el comprador cancele un pedido de productos agrícolas y alimentarios perecederos en un plazo tan breve que el proveedor no pueda razonablemente esperar encontrar una alternativa para comercializar o utilizar esos productos.

El precepto no prohíbe la cancelación en términos absolutos. Prohíbe la cancelación de un pedido únicamente cuando se notifica la misma con un plazo inferior a 30 días por considerarlo demasiado breve que tiene un efecto perjudicial para el proveedor. Sabemos que el art. 1256 del Código Civil establece que: "La validez y cumplimiento de los contratos no puede dejarse al arbitrio de uno de los contratantes". A tenor de este precepto, el comprador no tiene derecho a cancelar un pedido unilateralmente, salvo que así se le reconozca en las condiciones pactadas, aun así, no tendría derecho si el plazo es inferior a 30 días, límite del posible derecho a cancelar el pedido -art. 3.1. b)-. Una modificación inferior a 30 días es un plazo demasiado breve, salvo en ciertos sectores específicos que los Estados miembros de la Unión Europea entiendan justificadamente que unos plazos de cancelación más breves podrían dejar todavía tiempo suficiente para que los proveedores vendan los productos en otro lugar o le den ellos mismos uso.

${ }^{37}$ Ibidem, considerando $21 \mathrm{y}$ art. 3.1. c.

${ }^{38}$ Ibidem, considerando 16.

${ }^{39}$ En el caso de España, el art. 12 de la Ley de la Cadena Alimentaria en lo relativo a las modificaciones unilaterales sobrevenidas, las prohíbe con carácter general, sin perjuicio del tratamiento específico de la modificación sobrevenida de los plazos de pago, lo cual podría mantenerse ya que la Directiva permite la existencia de normas nacionales más estrictas. 
3.1.3. En tercer lugar, los proveedores y los compradores de productos agrícolas y alimentarios deben negociar libremente las transacciones comerciales incluido el precio, así como los pagos por servicios prestados por el comprador al proveedor -vg. la comercialización y la promoción-, estando prohibidas por desleales las prácticas por las cuales un comprador imponga a un proveedor pagos que no estén relacionados con una transacción de venta concreta ${ }^{40}$.

A tenor de lo establecido en el art. 3.1 letras d), e), i) de la Directiva, se consideran prácticas comerciales desleales que el comprador exija al proveedor los pagos que no están relacionados con la venta de los productos agrícolas o alimentarios del proveedor y que, por ejemplo, sirven en realidad para compensar al comprador de costes adicionales en los que se incurre para la comercialización de los productos, trasladando injustificadamente costes al proveedor.

El apartado e) del art. 3.1 considera práctica comercial desleal que el comprador exija al proveedor que pague el deterioro o la pérdida, o por ambos motivos, de productos agrícolas o alimentarios, ocurridos en el local del comprador o cuando ya se había transmitido la propiedad al comprador, sin que dicho deterioro o pérdida se deban a negligencia o culpa del proveedor.

Igualmente, en el apartado i) del art. 3.1 se considera práctica desleal que el comprador exija compensación al proveedor por los gastos derivados de estudiar las reclamaciones de los clientes relativas a la venta de los productos del proveedor, aun cuando no haya ni negligencia ni culpa por parte del proveedor ${ }^{41}$.

3.1.4. En cuarto lugar, en lo relativo a la exigencia de documentación por escrito, hay que estar a lo que establece el art. 3.1. f. Es necesario que los contratos de suministro agrícola y alimentario queden documentados por escrito con el fin de dejar constancia de las condiciones inicialmente pactadas, para así ofrecer protección frente a las modificaciones unilateralmente impuestas por el comprador ${ }^{42}$. La Directiva prohíbe como práctica comercial desleal que el comprador se niegue a confirmar por escrito los términos de un contrato de suministro que fueron acordados entre el com-

${ }^{40}$ Directiva (UE) 2019/633, considerando 22 y art. 3.1. d.

${ }^{41}$ Sobre este particular vide el art. 12.2 de la Ley de la Cadena Alimentaria y su posible reforma para su armonización con lo dispuesto en el art. 3.1. i) de la Directiva.

${ }^{42}$ F.J. Arias Varona, La armonización europea ..., p. 6, en el Ordenamiento Jurídico Español "la documentación por escrito sólo se reclama para las relaciones en las que se da un cierto nivel de desequilibrio que no se acomoda a la regla codificada en la Directiva. Esto, sin duda, exigirá una reforma legal pues los criterios europeos aseguran un mayor nivel de protección, a mi juicio, que lo dispuesto en el art. 2.3 de la Ley de la Cadena Alimentaria". 
prador y el proveedor y cuya confirmación por escrito le haya solicitado el propio proveedor ${ }^{43}$.

Para la Directiva no es obligatorio que los contratos se formalicen por escrito. Sin embargo, la formalización de los contratos por escrito en la cadena de suministro agrícola y alimentario puede evitar determinadas prácticas comerciales desleales. Por consiguiente, al objeto de proteger a los proveedores de las susodichas prácticas, éstos o sus asociaciones deben tener el derecho de solicitar una confirmación por escrito de las condiciones de un contrato de suministro cuando ya se hayan convenido. Por tanto, la Directiva califica como práctica comercial desleal, $\mathrm{y}$, por tanto la prohíbe, la denegación por parte de un comprador de la confirmación por escrito de las cláusulas del contrato de suministro ${ }^{44}$. Así, se considera práctica comercial desleal que el comprador se niegue a confirmar por escrito los términos de un contrato de suministro acordado, y que lo haya solicitado el proveedor ${ }^{45}$.

En suma, la Directiva no impone la formalización del contrato de suministro por escrito, ni tampoco un contenido mínimo del mismo. Lo que se prohíbe es que el comprador se niegue a confirmar por escrito los términos del contrato pactado si el proveedor se lo exige.

3.1.5. En quinto lugar, el art. 3.1.g) considera práctica comercial desleal a prohibir que el comprador adquiera, utilice o divulgue secretos comerciales del proveedor ilícitamente ${ }^{46}$. Con la prohibición de tales comportamientos no se protege tanto a los proveedores de productos agrarios o alimentarios, sino a determinados fabricantes frente a las grandes distribuidoras ${ }^{47}$.

${ }^{43}$ Según el art. 3.1. f) esto no será aplicable cuando el contrato de suministro se refiera a productos que deban ser entregados por un miembro de una organización de productores, incluido una cooperativa, a la organización de productores de la que es miembro el proveedor, cuando los estatutos de dicha organización de productores o las normas y decisiones estipuladas en ellos o derivados de las mismas incluyan disposiciones que tengan un efecto similar a los términos del contrato de suministro."

44 Directiva (UE) 2019/633, considerando 23.

${ }^{45}$ Según el art. 3.1. f “...esto no será aplicable cuando el contrato de suministro se refiera a productos que deban ser entregados por un miembro de una organización de productores, incluida una cooperativa, a la organización de productores de la que es miembro el proveedor, cuando los estatutos de dicha organización de productores o las normas y decisiones estipuladas en ellos o derivados de los mismos incluyan disposiciones que tengan un efecto similar a los términos del contrato de suministro".

${ }^{46}$ En el sentido de la Directiva (UE) 2016/943 del Parlamento Europeo y del Consejo de 8 de junio de 2016, relativa a la protección de los conocimientos técnicos y la información empresarial no divulgada (secretos comerciales) contra su abstención, utilización y revelación ilícitos (DOL 157 de 15.6.2016, p. 1).

${ }^{47}$ Para F.J. Arias Varona, La armonización europea..., p. 8, viene a corresponder con lo que establece el art. 13 de la Ley de la Cadena Alimentaria, y que con la transposición de la Directiva 
3.1.6. En sexto lugar, el art. 3.1. h) contempla como práctica estrictamente prohibida que el comprador amenace con llevar a cabo, o lleve a cabo, actos de represalia comercial contra el proveedor cuando éste ejerza sus derechos contractuales o legales, incluida la presentación de una denuncia o la cooperación con las autoridades de ejecución durante una investigación.

El uso de la amenaza o la ejecución de la misma puede ser frecuente, vg. la reducción de las cantidades de productos encargados. El uso de presiones indebidas y, en concreto, la amenaza de tomar represalias en la relación comercial si no se aceptan las condiciones impuestas por el comprador lleva a la Directiva a su prohibición. En el Considerando 25 de la Directiva se pone de manifiesto algunos de los comportamientos: vg. amenazar con tomar represalias o llevar a cabo la reducción de las cantidades de productos encargados con el propósito de imponer al proveedor la aceptación de determinadas condiciones desventajosas para él o impedirle hacer uso de los mecanismos legales de defensa o de denuncia ${ }^{48}$.

\subsection{Prácticas prohibidas, salvo si hay pacto previo, claro y expreso}

Según el art. 3.2, los Estados miembros se asegurarán de que queden prohibidas, como mínimo, todas las prácticas comerciales establecidas en las letras a) hasta la f), a menos que hayan acordado previamente de manera clara y sin ambigüedad en el contrato de suministro o en cualquier contrato posterior entre el proveedor y el comprador. En el caso de que lo que se hubiese acordado en éste hubiese sido el pago, el mismo se debe basar en estimaciones objetivas y razonables.

Se incluyen ciertas prácticas comerciales que quedan prohibidas, si bien se pueden tolerar en la medida en que se hayan acordado previamente de manera clara y sin ambigüedad en el propio contrato de suministro o cualquier otro contrato posterior ${ }^{49}$ entre el proveedor y el comprador, perseverando así la libertad de contratación entre las partes.

2019/633, aconseja la modificación de la susodicha ley con remisión a lo establecido en la Ley 1/2019 de Secretos Empresariales.

48 Para F.J. Arias Varona, La armonización europea..., p. 9, esta práctica no está prohibida por la genérica prohibición del abuso de situación de dependencia económica del art. 16 de la Ley de Competencia desleal, por lo que la transposición de la Directiva exige que se incorpore a la Ley de la Cadena Alimentaria.

49 Para F.J. Arias Varona, La armonización europea..., p. 9: "La referencia que se realiza en el texto a otro contrato posterior al de suministro no puede entenderse en el sentido de amparar modificaciones retroactivas al amparo de una novación posterior". 
El pacto previo, claro y sin ambigüedad entre el comprador y el proveedor permite las prácticas comerciales ${ }^{50}$ relacionadas en el art. 3.2., que, por otra parte, se refieren mayoritariamente a la exigencia de pagos adicionales o la imposición de obligaciones en las que se evidencia un claro desequilibrio entre las partes ${ }^{51}$.

El elenco de prácticas comerciales previstas en el art. 3.2. reflejan el traslado al proveedor de costes de actividades o riesgos que deben, en principio, asumirlos el comprador. El que las susodichas prácticas comerciales no queden automática y totalmente prohibidas se explica en ciertos casos, por ejemplo, en que se estimula la venta del producto del proveedor.

En los susodichos términos han de quedar prohibidas, como mínimo, todas las siguientes prácticas comerciales:

a) Que el comprador devuelva productos agrícolas y alimentarios no vendidos al proveedor sin pagar por estos productos no vendidos, o su eliminación, o ambas cosas;

b) Que se cargue al proveedor un pago como condición por el almacenamiento, la exposición o la inclusión en una lista de precios de sus productos agrícolas y alimentarios, o su puesta a disposición en el mercado ${ }^{52}$;

c) Que el comprador exija al proveedor que asuma total o parcialmente el coste de aquellos descuentos de los productos agrícolas y alimentarios vendidos por el comprador como parte de una promoción en tiendas y campañas de venta ${ }^{53}$ :

"Los Estados miembros de la Unión Europea velarán por que queden prohibidas las prácticas comerciales, a que se refiere la letra c) del párrafo primero, a menos que el comprador, antes de la promoción, iniciada por él, especifique la duración de la misma y la cantidad prevista de los productos agrícolas y alimentarios que vayan a entregarse a precio con descuento";

${ }^{50}$ F.J. Arias Varona, La armonización europea..., p. 10, entiende que "la normativa española es parcialmente más restrictiva que la Directiva europea, ya que el art. 12 de la Ley de la Cadena Alimentaria prohíbe cualquier pago adicional sobre el precio pactado, salvo si se refiere al riesgo razonable de referenciación de un nuevo producto o a la financiación parcial de una promoción reflejada en el precio unitario de venta (y siempre que se hayan pactado expresamente en el contrato).

${ }^{51}$ Según el art. 3.3. de la Directiva 2019/633 "Cuando el comprador solicite un pago por las situaciones descritas en el apartado 2, párrafo primero, letras b), c), d), e) o f), el comprador facilitará al proveedor, en caso de que este así se lo solicite, por escrito una estimación de los pagos por unidad o de los pagos por el total, según proceda, y, además, si se trata de las situaciones descritas en el apartado 2, párrafo primero, letras b), d), e) o f) también le facilitará, por escrito, una estimación de los gastos y la base de dicha estimación.

${ }^{52}$ Suele ser el comprador el que asume estos costes y si se hubiese acordado por el proveedor debe basarse en estimaciones objetivas y razonables. Directiva (UE) 2019/633, considerando 26.

${ }^{53}$ Ibidem, considerando 27. 
d) Que el comprador exija al proveedor que pague la publicidad de productos agrícolas y alimentarios realizada por el comprador;

e) Que el comprador exija al proveedor que pague por la comercialización por parte del comprador de productos agrícolas y alimentarios;

f) Que el comprador cobre al proveedor por el personal de acondicionamiento de los locales utilizados para la venta de productos del proveedor.

\section{Conclusiones}

El Reino de España, a más tardar, el 1 de mayo de 2021 ha debido adoptar las medidas legales necesarias para dar cumplimiento a lo establecido en la Directiva (UE) 2019/633, pudiendo optar por una transposición de mínimos o por una más amplia. La primera opción implicaría ceñirse a los actos desleales mediante una regulación y control administrativo modificando la Ley 12/2013, de 2 de agosto, de medidas para mejorar el funcionamiento de la cadena alimentaria. En cambio, la opción de una protección más amplia requiere incorporarla en la Ley 12/2013, con la posibilidad de un amplio ejercicio de acciones civiles por la realización de conductas contempladas en la Directiva.

La Directiva (UE) 2019/633 representa una clara intervención de la UE en las prácticas comerciales desleales en las relaciones entre empresas en la cadena de suministro agrícola y alimentario, adoptando normas imperativas que prohíben determinadas prácticas comerciales desleales en la Cadena Alimentaria: retraso en el pago de productos agroalimentarios ya entregados (con ciertas particularidades en el sector vitivinícola), cancelación unilateral tardía de un pedido o su modificación retroactiva, el rechazo del comprador a formalizar por escrito un contrato con el proveedor, el uso incorrecto de información confidencial, amenazar al proveedor con dejar de comprar sus productos o rechazar los pagos si el poseedor presenta alguna reclamación, solicitar compensaciones económicas en caso de deterioro o pérdida de los productos una vez entregados, a menos que ese deterioro se deba a una negligencia del proveedor.

La Directiva asegura una protección mínima común de los proveedores en la cadena de suministro agrícola y alimentario, si bien su extensión a compradores de Estados que no son miembros de la UE afecta a la extraterritorialidad de la norma, lo que plantea dudas.

Ley española de la Cadena Alimentaria encaja en la reserva que hace la Directiva de la posibilidad de que la legislación interna de los Estados miembros incluya normas más protectoras, por lo que resulta muy limitada la necesidad de su modificación para adecuar el contenido del susodicho 
texto legal al contenido de la Directiva. Aun así, se requiere unas modificaciones de la susodicha Ley para incorporar ciertos aspectos de la Directiva, en particular las referidos a las amenazas con represalias y a la garantía del anonimato del denunciante ante el órgano administrativo - AICA-.

La transposición de la Directiva es compatible con sistemas de autorregulación que permite el mantenimiento de las soluciones convencionales que existen en el Ordenamiento Jurídico patrio: el Código de Buenas Prácticas Mercantiles en la Contratación Alimentaria.

La Directiva (UE) 2019/633 preserva la validez de los Códigos de Buenas Prácticas Mercantiles en la Contratación Alimentaria y estimula otras medidas como adecuado complemento a la normativa vigente sobre el particular. Al tratarse tales Códigos de un Sistema de adhesión voluntaria, su utilidad dependerá del grado de aceptación y de las garantías de su respeto, lo que requiere órganos específicos de control, con facultades de inspección y sanción reforzadas, así como reglas procedimentales propias. Para ello, el art. 4 de la Directiva contempla la existencia de autoridades específicas encargadas de la aplicación de la susodicha norma y de la vigilancia de los comportamientos.

En el Reino de España se atribuyen estas competencias de las materias relativas a la Ley de la Cadena Alimentaria a la Agencia de Información y Control Alimentarios-AICA-. Por otra parte, se ha criticado la ausencia de un sistema de legitimación que preserve la confidencialidad del denunciante, incluyendo, al modo de cómo lo hace la Directiva, un sistema de legitimación amplio que incluye también a organizaciones de productores $u$ otros proveedores. Desde la perspectiva del desequilibrio entre las partes de las relaciones comerciales en la cadena de suministro agrícola y alimentario, resulta esencial que los proveedores puedan acudir a la Administración competente para que realicen las oportunas inspecciones e impongan, en su caso, las correspondientes sanciones por haber realizado prácticas comerciales desleales ${ }^{54}$. Se trata de proteger al proveedor denunciante para lo que se dispone una forma de ejercitar las facultades de la Administración, preservando el anonimato del denunciante para lograr la máxima eficacia de la norma.

Por último, señalar como novedad que el Real Decreto-Ley 5/2020, de 25 de febrero que contempla medidas en materia de agricultura y alimentación, modificando la Ley de cadena alimentaria, prohíbe la venta a pérdidas, estableciendo la obligación de cada operador de abonar al inmediatamente anterior un precio igual o superior al coste de producción de tal producto en que haya incurrido dicho operador, de modo que se preserve su valor

${ }^{54}$ Ibidem, art. 5.3. 
agregado. Asimismo, se impide que el operador que realice la venta final del producto al consumidor pueda repercutir a ninguno de los operadores anteriores el riesgo empresarial derivado de su política comercial en materia de precios ofertados al público. Por último, se incluye el coste efectivo de producción en el precio como elemento mínimo de los contratos.

\title{
DIRECTIVE (EU) 2019/633 ON UNFAIR COMMERCIAL PRACTICES FOR A MORE SUSTAINABLE AGRICULTURAL AND FOOD SUPPLY CHAIN
}

\author{
Summary
}

\begin{abstract}
Generally, in all commercial negotiations in the agricultural and food supply chain, the bargaining power enforces reduced prices and an imposition of unfair contractual conditions which suppliers have to accept to avoid being excluded from the market. Contractual conditions that harm the weaker party with less negotiating power and no possibility of withdrawing from the commercial relationship, imposed by a party in a privileged position, are described as unfair commercial practices. What is more, they are not only detrimental to agri-food businesses, but also to consumers and the overall functioning of the market. The uneven bargaining power between buyers and suppliers in the agricultural and food supply chain, leading to commercial relationships lacking clarity, transparency and fairness may effectively proper functioning of the market.
\end{abstract}

\section{LA DIRETTIVA (UE) 2019/633 IN MATERIA DI PRATICHE COMMERCIALI SLEALI NEI RAPPORTI TRA IMPRESE NELLA FILIERA AGRICOLA E ALIMENTARE}

\section{Riassunto}

In generale, in qualsiasi trattativa commerciale avviata lungo la filiera agroalimentare, il vantaggio negoziale porta, in molte situazioni, a forzare prezzi più bassi ed a imporre clausole contrattuali abusive, le quali i fornitori sono costretti ad accettare per evitare di essere esclusi dal mercato. Tali condizioni contrattuali, imposte dalla parte in posizione privilegiata e svantaggiose per la parte più debole, cioè la parte con minore potere negoziale e praticamente incapace di recedere da questo tipo di rapporto commerciale, sono definite pratiche commerciali sleali. Esse rappresentano una minaccia non solo per le imprese agroalimentari, ma anche per i consumatori stessi nonché per il funzionamento del mercato. Uno squilibrio presente nel potere negoziale tra acquirenti e fornitori nella catena alimentare può ostacolare il corretto funzionamento del mercato portando ad escludere le relazioni commerciali basate su chiarezza, trasparenza ed equità. 